\title{
Effects of turmeric rhizome powder and curcumin on poultry production. A review
}

\author{
J.L. Guil-Guerrero',2,4, L. Ramos ${ }^{3}$, J.C. Zúñiga Paredes², M. Carlosama-Yépez², C. Moreno² \\ and P. Ruales ${ }^{2}$ \\ ${ }^{1}$ University of Almería, Department of Agronomy, 04120 Almería, Spain \\ ${ }^{2}$ Ecuadorian Agency for Quality Assurance in Agriculture, AGROCALIDAD, km 141/2 Tumbaco, Ecuador \\ ${ }^{3}$ Equinoccial Technological University, Faculty of Engineering Sciences and Industries, Food Research Centre, \\ EC171029 Quito, Ecuador
}

KEY WORDS: turmeric powder, curcumin, poultry production, bird's health

Received: 31 December 2016

Revised: $\quad 16$ March 2017

Accepted: 3 November 2017

${ }^{4}$ Corresponding author:

e-mail: jlguil@ual.es

\begin{abstract}
Nowadays, alternative feed supplements enhancing bird health are sought by poultry producers. Among different herbs and supplements, turmeric (Curcuma longa L.), which contains bioactive secondary metabolites as curcuminoids, has been successfully used as a suitable feed supplement for poultry. It induces a wide range of positive actions in birds, namely: 1 . improvement of several haematological and biochemical indicators, 2. increase of antibody titers after vaccination (e.g., against Newcastle disease), 3. diminishment of heat stress by different mechanisms, 4 . prevention from harmful effects of aflatoxins consumed together with diet, 5 . increase of antioxidant activity of several organs (e.g., spleen), 6. decrease in some potentially pathogenic bacteria counts, i.e. Escherichia coli, in the ileal content of the farmed laying hens. The aim of this review is to describe and analyse the use of turmeric as feed supplement for birds and its influence on animal health.
\end{abstract}

\section{Introduction}

With gradually rising human population an increasing demand for poultry meat is expected in the nearest future. For this reason poultry health is an important issue. Due to the extremely crowded henhouses and consequently poor hygiene, the antibiotics are extensively used to maintain health and activate bird growth (Van Boeckel et al., 2015). This is significant problem since antimicrobial resistance can be derived from the abusive usage of antibiotics, and thus greater regulatory efforts are needed (Landers et al., 2012; WHO, 2012). Moreover, in many countries there are laws and welfare codes protecting farm animals, including poultry, from distress and fear (Main, 2009; Bonafos et al., 2010). In line with the above require- ments, some plant-derived active compounds, as those present in turmeric, could be used to reduce antibiotic overuse and simultaneously increase animal welfare (Palaniappan and Holley, 2010).

Turmeric (Curcuma longa L.) is a popular medicinal herb, which shows a wide range of pharmacological properties, such as antioxidant, antiprotozoal, antivenom, antimicrobial, anti-inflammatory, antiproliferative, antiangiogenic, antitumor and antiaging (Amalraj et al., 2017). The use of turmeric in poultry production was formerly reviewed by Khan et al. (2012).

The aim of this review is to describe and analyse the most recent research on the use of turmeric as feed supplement for birds and so its effect on animal health and welfare. 


\section{Active constituents of turmeric rhizome powder (TRP)}

On average, TRP contains $6 \%$ crude protein, $5.1 \%$ crude fat, $3.5 \%$ minerals, $69 \%$ carbohydrates and $13 \%$ moisture (Chattopadhyay et al., 2004). Active constituents include curcuminoids (Figure 1), which refer to a group of chemically related active phenolics present in TRP, i.e. curcumin (diferuloylmethane), demethoxycurcumin and bisdemethoxycurcumin (Jurenka, 2009). Curcumin is an orange-yellow crystalline powder obtained by solvent extraction of TRP, and subsequent purification of extract done by crystallization. Curcumin has the nature of an oily soluble crystalline powder with a melting point at $174{ }^{\circ} \mathrm{C}$ (Sogi et al., 2010). Other active compounds of turmeric are essential oils (Figure 2), which are composed mainly by sesquiterpenes, most of them specific to the Curcuma genus.
The aroma of TRP is principally derived from $\alpha$ - and $\beta$-turmerones, and aromatic turmerone (ar-turmerone) (Ravindran et al., 2007). In percentages higher than $4 \%$ of the total compounds, it contains (in decreasing order): Z- $(\gamma)$-atalantone, E- $(\gamma)$-atalantone, S-(ar)-turmerone, $\beta$-sesquiphellandrene, $\alpha$-zingiberene, $\alpha$-turmerone, $\alpha$-zingiberene, 1,8 -cineole and arcurmenene (Chassagnez-Méndez et al., 2000).

\section{Biological activities of turmeric and its constituents}

The biological activities of the compounds present in TRP have been widely studied. The most important activities for poultry production are those mentioned below.

Antioxidant properties. Curcuminoids have powerful antioxidant activity, which has been evaluated both in in vitro and in vivo tests. The antioxidant<smiles>[R]c1cc(/C=C/C(=O)CC(=O)/C=C/c2ccc(O)c([R])c2)ccc1O</smiles>

Curcumin: (1E,6E)-1,7-Bis(4-hydroxy-3-methoxyphenyl)-1,6-heptadiene-3,5-dione; $\mathrm{R}_{1}=\mathrm{R}_{2}=\mathrm{OCH}_{3}$ Demethoxycurcumin: 1-(4--hydroxy-3-methoxyphenyl)-7-(4-hydroxyphenyl)-1,6-heptadiene-3,5-dione; $\mathrm{R}_{1}=\mathrm{R}_{2}=\mathrm{OCH}_{3}$ Demethoxycurcumin: 1,7-Bis(4-hydroxyphenyl)-1,6-heptadiene-3,5-dione; $\mathrm{R}_{1}=\mathrm{R}_{2}=\mathrm{H}$

Figure 1. Chemical structure of curcumonoids. Structures were drawn using ChemDraw Ultra software (Cambridge Soft Co., Cambridge, MA, USA)<smiles>CC(C)=CC(=O)CC(C)=C1CC=C(C)CC1</smiles><smiles>CCCCCCCCCC(=O)C=C(C)C</smiles><smiles>CC(C)=CC(=O)C[C@@H](C)c1ccc(C)cc1</smiles><smiles>C=C1C=CC(C(C)CCC=C(C)C)CC1</smiles><smiles>CC(C)=CCC[C@H](C)[C@H]1C=CC(C)=CC1</smiles><smiles>CC1=CCC(C(C)C)C=C1</smiles><smiles>CC(C)(C)CC1CCC2(C)CC2C1(C)C</smiles><smiles>CC(C)=CCCC(C)c1ccc(C)cc1</smiles>

Figure 2. Chemical structure of compounds contained in the essential oil of Curcuma longa L. Structures were drawn using ChemDraw Ultra software (Cambridge Soft Co., Cambridge, MA, USA) 
activity of curcumin is linked to the presence of phenolic groups in the molecule, and this activity can be related to anti-inflammatory, hepato- and cardio-protective effects of curcumin. Furthermore, it has been demonstrated that curcumin can be successfully used, along with standard drugs, as an adjuvant in a drug therapy of oxidative stress-induced diseases (Amalraj et al., 2017).

Anti-inflammatory activity. The action of curcumin against inflammation is affected by several molecular pathways, i.e. by reducing immune response, increasing xenobiotic metabolism, amelioration of inflammation by decreasing neutrophil migration and improving barrier remodelling. Overall, curcumin is a highly pleiotropic molecule, able to interact with numerous molecular targets leading to inflammation (Jurenka, 2009).

The inhibition of inflammatory cytokines is a typical action of several anti-inflamatory drugs - the one of the mechanisms which is affected by curcumin. It has been demonstrated in in vitro studies that curcumin regulates the activation of some transcription factors, such as activating protein-1 (AP-1) and nuclear factor kappa $\mathrm{B}(\mathrm{NF}-\mathrm{\kappa B})$ in stimulated monocytes and alveolar macrophages, thus blocks the expression of genes encoding cytokines (Jobin et al., 1999). On the other hand, in the in vivo studies it has been shown that curcumin also inhibits arachidonic acid metabolism and inflammation in mouse skin epidermis via down-regulation of the cyclooxygenase and lipoxygenase pathways (Huang et al., 1991).

Antiviral and antifungal activity. The in vitro activity of curcumin against influenza viruses was evaluated by Chen et al. (2010) with promising results. It was found that curcumin interrupts virus-cell links hindering the multiplication of the influenza virus and exerts a direct effect on viral particle infectivity. Furthermore, Zhang et al. (2012) tested the action of curcuminoids on Candida albicans growth with the use of microcalorimetry. Structural activity relationship confirmed that the existence of the methoxyl group might enhance lipophilicity of the mother nucleus, which made easier for the molecule to enter into the cell membrane of fungi inhibiting its growth.

Immunomodulatory properties. The polar fraction of $C$. longa has been tested for immunomodulatory activities on human peripheral blood mononuclear cells. This extract exhibited stimulatory effects on the proliferation of such cells, evaluated by the (methyl${ }^{3} \mathrm{H}$ )-thymidine incorporation assay. It was concluded that curcuminoids and polysaccharides can be used as potentially adjuvant supplement for cancer patients whose immune system was suppressed by chemo- therapy (Yue et al., 2010a). Furthermore, $\alpha$-turmerone and ar-turmerone have shown stimulatory effects on peripheral blood mononuclear cells proliferation and cytokine production (Yue et al., 2010b).

\section{Haematological, biochemical and immunological indicators of poultry health}

Some factors related to animal welfare may alter certain haematological markers. For instance, stress can influence haematological counts - it induces adrenocorticotropic hormone $(\mathrm{ACTH})$ secretion and subsequent release of epinephrine and norepinephrine that contribute to transient neutrophilia. This may affect the immune response since heterophils and neutrophils constitute the first line of defence with efficient chemotactic response against foreign, viable or innate agents (Kumari et al., 2007). Glucose is a serum biochemical marker that is widely analysed. Its reduced plasma level indicates its adequate utilization by tissues, possibly due to a stimulation of glucose transporters, which indicate a better use of energy. Further, glucose is utilized by birds for a variety of functions, mainly for energy production through cellular oxidation, glycogen synthesis in liver and glycolytic muscles, fatty acid synthesis as well as synthesis of nonessential amino acids, vitamin $\mathrm{C}$ and other metabolites (Braun and Sweazea, 2008). Another interesting serum marker is total protein, which seems to be related to a better ability of hepatocytes to synthesize protein, and so it indicates a better humoral immune status (Kumari et al., 2007). In birds, plasma concentration of uric acid is exceptionally high in comparison with other vertebrates. This fact has been suggested as a possible mechanism to protect birds from oxidative damage. Indeed, increased plasma concentration of uric acid in chickens reduces leukocyte oxidative activity while decreased concentrations are associated with increased leukocyte oxidative activity. Knowing that increased concentration of uric acid results from protein degradation, one of the consequences of increased protein catabolism during prolonged exercise may be an improved antioxidative defence resulting from the higher uric acid concentration (Tsahar et al., 2006).

In recent years, enzymatic assays have become an effective tool for understanding the poultry health. However, there is a high individual variation in enzyme activities among birds, so that data should be interpreted attentively. Enzyme activity in birds is affected by numerous factors, including age, sex, species, breed, nutrition, physiological state and farming methods. Enzyme activity analyses are crucial for determination whether oxidative stress reactions are 
induced in cells and which cells or organs have been damaged by this process. Oxidative stress is generally connected with increased activity of aspartate aminotransferase (AST), alanine aminotransferase (ALT), alkaline phosphatase (ALP) and lactate dehydrogenase (LDH); as well as to a decreased activity of superoxide dismutase (SOD) and glutathione peroxidase (GPx) (Ognik and Krauze, 2016). Generally, the use of feed components and supplements with antioxidants or immunostimulatory properties mitigates oxidative stress, which is manifested through suitable changes in the activity of these enzymes; thus, such activity is regularly evaluated to discern positive effects of different feed supplements.

On the other hand, changes in the plasma lipids of poultry can be too complex to interpret. For instance, high plasma levels of lipids in laying hens reflect the significant demand for yolk lipids by the growing oocytes. Other important fact to consider is that the low density lipoproteins (LDL) and very low density lipoproteins (VLDL) in meat-type chickens occur in much smaller proportions than high density lipoproteins (HDL). Furthermore, it is convenient to keep in mind that the plasma concentration of HDL in laying hens is depressed by 2- to 3-fold in comparison with mature hens or broilers. Also the bird age may influence the relationship between lipoprotein metabolism and egg production. The total number of eggs decrease in hens with increased blood LDL concentration; and highly productive hens produce little LDL (Musa et al., 2007).

Cytokines belong to a broad category of small proteins $(\sim 5-20 \mathrm{kDa})$ that are important in cell signalling. Besides that, lymphokines are a subset of cytokines that are produced by a type of immune cells known as T lymphocytes, being an effective tool for discerning the health status of poultry, given that the avian immune system operates on the same general principles as the mammalian (Sharma, 1991). Among the already identified cytokines in chickens, the most prominent are interleukine (IL)-1, IL-2, IL-4 and interferon (IFN)- $\gamma$. Interleukins play a physiological role in inflammation and a pathological role in systemic inflammatory status: IL-1 serves as a signal for the activation of $\mathrm{T}$ cells, and $\mathrm{T}$ cells, in turn, secrete IL-2; avian IFN- $\gamma$ plays a pivotal role in modulating cellular immunity: it activates macrophages, enhances natural killer cell activity, inhibits speciesspecific viral replication, and is known as $\mathrm{T}$ helper cell type 1 (Th1)-type cytokine (Sharma, 1991; Ohtsu et al., 2015); IL-4 is known as a Th2-type cytokine, which acts in humoral immunity (Ohtsu et al., 2015).

\section{Feeding trials using TRP or curcuminoids for improving bird health}

TRP or its extracts usage in poultry production is fairly recent examined. Performance, growth and some other parameters are widely evaluated, nevertheless the studies on unequivocal markers of animal health will be presented and discussed below.

It was stated that in chicken, TRP could increase beneficial cholesterol fractions (HDL) and haemoglobin $(\mathrm{Hb})$, while decreasing LDL-cholesterol, VLDLcholesterol, red blood cells (RBC), triacylglycerols (TAG) and blood albumin levels (Emadi et al., 2007; Kumari et al., 2007; Daneshyar et al., 2011; Nouzarian et al., 2011; Sugiharto et al., 2011; Faghani et al., 2014). Furthermore, Kumari et al. (2007) found that TRP induced a decrease in concentration of uric acid in serum (from 6.31 to $4.21 \mathrm{mg} \cdot \mathrm{dl}^{-1}$ ) and an increase in total protein content in serum (from 3.15 to $3.49 \mathrm{mg} \cdot \mathrm{dl}^{-1}$ ). In healthy birds these both levels are $\sim 5 \mathrm{mg} \cdot \mathrm{dl}^{-1}$ (Simaraks et al., 2004), thus, TRP might be used to revert pathophysiological effects like those induced by stress, in which protein catabolism is increased (Lin et al., 2006).

Concerning plasma lipids, the use of pure curcumin at low doses in feed reduces cholesterol level in broilers (Rajput et al., 2013), while the same effect of TRP is possible when it is used at high amounts, up to $1 \mathrm{~g} \cdot \mathrm{kg}^{-1}$ feed.

TRP has been reported to induce positive effects on enzymes and hormones that directly or indirectly reflect the health status of broilers, and has been essayed to ameliorate the harmful effect of heat stress in such birds, which are highly susceptible to this due to high production performance and feed conversion ratio (FCR). For instance, such stress increases serum AST activity, which is $\sim 37 \mathrm{Unit} \cdot \mathrm{ml}^{-1}$ in 20-day old free-stress birds (Kumari et al., 2007). At the same time, cortisol value in those animals is $\sim 1.15 \mu \mathrm{g} \cdot \mathrm{dl}^{-1}$ (Swathi et al., 2012a). Furthermore, heat stress exerts negative effects on the immune response in broiler chickens, e.g., spleen, is atrophied by its presence, and as a consequence the expression of splenic cytokines such as IL-12 and IFN- $\gamma$ is changed (Ohtsu et al., 2015).

Nutritional strategies are focused on alleviating the negative effects of heat stress by supplementing medicinal herbs and micronutrients, i.e. vitamins and minerals, to satisfy the special needs during heat stress, which have been proven to be advantageous (Lin et al., 2006). In this regard, strategies using TRP or curcuminoids in bird diets have been implemented. For such experiments, stress is usually applied for 
5-8 $\mathrm{h} \cdot$ day $^{-1}$, at $33-34{ }^{\circ} \mathrm{C}$, and to discern the protective effects of such feeding, lipid metabolism, blood metabolites, immune system and the antioxidant status before and after heat stress are determined. Also, feeding trials using cold stress have been carried out using curcumin up to $1000 \mathrm{ppm}$ in feed, which induces a significant increase in GPx activity, although the most effective dose was $50 \mathrm{ppm}$ (Éclache et al., 2011).

Different feeding trials resulted in the favourable effects of TRP on heat-stressed poultry. The main findings are: 1 . low blood total cholesterol and LDL-cholesterol concentrations and high cholesterol HDL fraction in birds fed diet supplemented with TRP at pre- and after-application of heat stress, 2. TRP-induced decreased activity of several enzymes usually increased in heat-stressed birds, i.e. LDH, AST, ALT and ALP, 3. improved by TRP blood activity of GPx and SOD, which protects the organism from the oxidative damage; 4 . decreased by TRP blood thiobarbituric acid reactive substances (TBARS) index, an indicator of oxidative damage, and 5. TRP-reduced malondialdehyde (MDA) concentrations, which indicates an improved antioxidant and detoxifying status of birds (Emadi and Kermanshahi, 2007; Hosseini-Vashan et al., 2012, 2015; Wang et al., 2015). In this line of research, pure curcumin has been tested in heat-stressed quails, and it was established that curcumin ameliorates heat stress through modulating the hepatic nuclear transcription factors and heat shock protein 70 (Sahin et al., 2012).

TRP or curcuminoids have been successfully applied to raise the immune status of farm birds after vaccination, it was noted that antibody titers were increased by supplementation with turmeric in feed (Faghani et al., 2014). Such effect would be very useful when vaccinating against Newcastle disease, a highly contagious viral disease for poultry, which causes significant economic losses. Unfortunately, the vaccination could not prevent a disease occurrence in farm conditions (Moomivand et al., 2013), therefore, strategies seeking to increase the immune response by co-administration of herbal preparations for improving antibody titers after Newcastle disease virus (NDV) vaccination have been implemented, and it was found that TRP increases the humoral response (Kumari et al., 2007). Furthermore, in the post-vaccination periods for other avian infectious viruses, such as the infectious bronchitis virus (IBV) and infectious bursal disease (IBD), TRP induces higher IBV- and IBD-specific antibody titers (Qasem et al., 2015).
Coccidiosis is an enteric disease caused by several Eimeria species, which represents one of the highest economic problems for the poultry industry. Live Eimeria vaccination stimulates immunity; however, the success of a live coccidiosis vaccine is linked to poultry management techniques, and the use of stimulators of immunity to achieve high antibody titers is desirable (Price et al., 2013), so that alternate methods for control of coccidiosis are limited. TRP has been tested on innate immunity and protective immunity against $E$. acervulina infection. It was noted that in the coccidiosis-infected chickens fed TRP at a dose of $5 \mathrm{mg} \cdot \mathrm{kg}^{-1}$ live weight reduced faecal oocysts, and higher serum antibody titers and transcripts encoding cytokines (IL-6, IL-15 and IFN- $\gamma$ ) were found in comparison with birds fed only standard diet (Lee et al., 2010).

Aflatoxins (AF), frequent in maize-based feed, causing hepatotoxic and hepatocarcinogenic effects, constitute another serious problem in poultry production (da Rocha et al., 2014). Poultry are extremely sensitive to the toxic and carcinogenic actions of $\mathrm{AFB}_{1}$, and annually producers suffer high losses due to reduced growth rate and several other adverse effects. The extraordinary sensitivity to $\mathrm{AFB}_{1}$ is associated with efficient hepatic cytochrome P450mediated bioactivation and deficient detoxification by glutathione S-transferases (GST) (Rawal et al., 2010). In experiments designed to ameliorate the effects of aflatoxin through TRP intake, AF was administered to birds up to $1 \mathrm{ppm}$ in diets, or $30 \mu \mathrm{g} \cdot \mathrm{kg}^{-1}$ live weight per day, while the basal diet contained TRP up to $0.5 \%$, which correspond to $\sim 150 \mathrm{mg} \cdot \mathrm{kg}^{-1}$ of curcumin. It was found that the addition of TRP to the AF diets ameliorated the negative effects of AF on growth performance and liver weight (Yarru et al., 2009; Ahmadi, 2010). Furthermore, the inclusion of TRP in $\mathrm{AFB}_{1}$ diets alleviates the increased expression of immune system genes due to such toxin, as well as TRP $(0.5 \%$ feed $)$ results in increased expressions of IL-2 and IL-6 (Yarru et al., 2009); counteracts the adverse effects of $\mathrm{AFB}_{1}$ on serum metabolites such as proteins, uric acid and glucose; prevents the decreased antioxidant status caused by $\mathrm{AFB}_{1}$ (Ahmadi, 2010), and also, increases ALT and AST activities, and cholesterol, TAG and lipid peroxidation levels (Ayoub et al., 2011).

Other effects of TRP supplementation are: an increase in serum levels of $\mathrm{Mn}, \mathrm{Zn}, \mathrm{Fe}$ and $\mathrm{Cu}$ (Kumari et al., 2007); an improvement of plasma thyroxine (T4) level and fat utilization, which led to a better utilization of the apparent metabolizable energy (Rajput et al., 2013), and the simultaneous decrease in 
Escherichia coli populations in parallel with increased Lactobacillus spp. counts (Faghani et al., 2014).

\section{Feeding trials using TRP in conjunction with other active agents to maintain good health in farmed birds}

As previously indicated, TRP has been used in combination with other agents with different purposes, for instance to avoid adverse effects of heat stress in poultry production. To this end, TRP and sodium selenite alone and combined have probed efficacy on decreasing triiodothyronine (T3), while its interaction decreased plasma cholesterol and TAG concentration (Zeinali et al., 2011).

Tulsi (Ocimum sanctum) is a small herb that is characterized by a broad spectrum of anti-infective properties, developing antifungal and antibacterial actions, with eugenol as active constituent (Prakash and Gupta, 2005). The combination of TRP with tulsi had beneficial effects on heat-stressed broilers, while TRP exerted better effects than tulsi in improving several haematological parameters in birds (Swathi et al., 2012b). Furthermore, tulsi and TRP at a dose of 0.5 and $0.4 \%$ feed, respectively, lowered the activity of serum enzymes and concentration of cortisol and simultaneously increased total protein, albumin and globulin content in comparison with heath-stressed birds fed control diet (Swathi et al., 2012b).

Also using TRP in combination with other components as betaine, zeolites or capsaicin can be another valuable solution. Betaine is an osmolyte that can be used in order to help thyroxine to maintain cellular water and ion balance in animals, which spares valuable metabolic energy. Its use improves carcass lean deposition, particularly under stress. Combinations of TRP and betaine to circumvent the effects of heat stress have been also tested, and several serum biochemical parameters used as stress indicators were improved. On the other hand, the serum concentration of MDA induced by heat stress decreased by TRP supplementation, while antioxidant and detoxifying enzymes improved activities in the supplemented groups (Akhavan-Salamat and Ghasemi, 2016).

Several years ago, it was discovered that the inclusion of zeolite (a hydrated aluminosilicate), especially zeolite A, into diets helped animals to endure or resist the negative effects that are associated with excessive heat conditions (Laurent and Sanders, 1988). Trying to achieve high antibody titers against coccidiosis, the efficacy of TRP with aluminosilicate has been tested on haematological and parasitological parameters, and it was found that such combination improves $\mathrm{Hb}$ content and packed cell volume (PCV) in broilers (Singh et al., 2009).
The Clostridium-related poultry disease, necrotic enteritis, causes significant economic losses in poultry farms. Capsicum oleoresin has been proposed to reduce the incidence of this disease, considering its well-known anti-inflammatory and antibiotic effects in human and veterinary medicine (Kim et al., 2010). Capsicum and TRP oleoresins jointly applied to broiler chickens infected with Clostridium perfringens, Eimeria maxima and oocysts has been probed successfully to reduce gut lesion scores, while such combination decreased serum $\alpha$-toxin levels and several intestinal cytokines levels, among other beneficial effects (Lee et al., 2013).

Amla (Phyllanthus emblica L.) is a medicinal plant that contains phenolic compounds, displaying anti-inflammatory, antibacterial, antioxidant and chemopreventive properties (Mirunalini and Krishnaveni, 2010). Trying to stimulate the bird immune system, a mixture of TRP, amla and tulsi, was tested in broiler chickens. It was found that the immune response, measured as the highest dilution of serum that inhibits haemaglutination (HI titre), to NDV vaccination slightly increased (Tirupathi Reddy et al., 2012).

Black pepper (Piper nigrum L., BP) is a species acting as antiapoptotic, antibacterial, antifungal, antidiarrhoeal, anti-inflammatory, antimutagenic, antitumoral and hepatoprotective additive (Ahmad et al., 2012). Coriander seeds (Coriandrum sativum L., CS) constitute a natural antioxidant able to inhibit unwanted oxidation processes (Wangensteen et al., 2004). It was found that the combined use of TRP, CS and BP was adequate to improve the immune response after NDV vaccination (AbouElkhair et al., 2014).

Garlic (Allium sativum L., AS) is a food ingredient with antimicrobial, antioxidant, immunomodulatory and prebiotic activities (Corzo-Martínez et al., 2007), while black cumin (Nigella sativa L., NS) has immunomodulatory and immunotherapeutic potential (Salem, 2005). In connection with the fact that poultry are often vaccinated against IBD simultaneously to NDV, TRP was used in conjunction with AS and NS trying to improve antibody titers against IBD, and best value was noted using NS (Ali et al., 2014).

Some experiments were carried out using TRP in conjunction with other agents, e.g., vitamins, enzymes and medicinal plants, to evaluate health indicators in general, without checking them against specific subjects. Good results were obtained in biochemical and haematological analyses of PCV, blood uric acid, glucose, TAG, cholesterol fractions, 
liver enzymes, inflammatory markers and oxidative stress indicators (Mehala and Moorthy, 2008; Ashayerizadeh et al., 2009; Akbarian et al., 2012; Nayaka et al., 2013; Kilany and Mahmoud, 2014; Mahejabin et al., 2015; Santoso et al., 2015).

Furthermore, many researchers evaluate the effects of TRP and mannan-oligosaccharides on intestinal bacteria in broilers. Functional oligosaccharides are effective in gastrointestinal normal flora proliferation and pathogen suppression (Patel and Goyal, 2011). The combination of such additive with TRP produced a remarkable inhibition of duodenal coliform bacteria, yeast and mould in the caecum and all viable microbes in the ileum (Samarasinghe et al., 2003).

\section{Feeding trials using TRP or its extracts, and TRP in conjunction with other active agents to improve the health of laying hens}

Like in broilers, most experiments on laying hens deal with the use of TRP to improve biochemical parameters in blood, such as cholesterol fractions, as well as to decrease serum AST and ALT activities and TAG concentration. In all cases, TRP has been successfully used. For instance, Kermanshahi and Riasi (2006) indicate a decrease of 63.9, 50.2 and $63.3 \%$ for TAG, total- and LDL-cholesterol levels, respectively, while HDL-cholesterol content was raised up to $15 \%$. Similar results were obtained by many other authors (e.g., Malekizadeh et al., 2012; Riasi et al., 2012; Arshami et al., 2013; Saraswati et al., 2013; Mirbod et al., 2017). Concerning enzyme activities, Malekizadeh et al. (2012) found that AST and ALT activities decreased by 5.1 and $19.0 \%$, in line with the results of Mirbod et al. (2017) and Saraswati et al. (2013).

On the other hand, TRP improves laying hen immunity, since it increases total immunoglobulins (Ig) and IgG titers after sheep red blood cells (SRBC) injections (Arshami et al., 2013), and TRP boosted the immune response to NDV and SRBC antigens, although feeding TRP also decreased the heterophils:lymphocytes ratio (Mirbod et al., 2017). Another interesting effect of TRP supplementation is a decrease of $E$. coli counts in the ileal content of farmed laying hens (Mirbod et al., 2017).

\section{Possible toxicity of TRP and effects on morphological indicators}

The use of TRP in poultry production seems to be safe. Concerning broiler chickens, AL-Sultan and Gameel (2004) found that turmeric at high doses (2.5, 5.0 and $10.0 \%$ of feed given for several weeks) induced parenchymal and portal infiltration of mononu- clear cells and hyperaemia of portal vessels in liver. Considering TRP doses usually used in the feeding trials reviewed here, which are below $2 \%$ in all cases, it can be concluded that such level of inclusion of TRP in poultry diets is toxicologically safe.

Performance indicators are also noticeable. In the vast majority of experiments conducted with TRP or curcuminoids, or TRP in conjunction with other active agents, most of these indexes were improved, such as body weight gain, FCR, feed intake and growth performance, while in laying hens TRP feeding increased egg production, and in broilers it lowered abdominal fat.

\section{Conclusions and future trends}

Tumeric rhizome powder (TRP) contains bioactive secondary metabolites and curcuminoids that are needed to produce heathly poultry. Besides the good results of bird performance, TRP inclusion into feed induces positive actions on blood biochemical parameters, such as the enhancement of the activities of antioxidant and detoxifying enzymes. It also improves antibody titers in the post-vaccination periods, counteracts the harmful effects of aflatoxins provided with diet, and decreases some potentially pathogenic bacteria counts in the ileal content of farmed laying hens. Furthermore, TRP may be used successfully to ameliorate heat stress in poultry.

All studies on the use of TRP in poultry are recent, and describe the widespread use of antibiotics in animal production, as well as its expected progressive withdrawal - comparative research on turmeric vs antibiotic will be very interesting and useful. Specifically, setting precise doses to prevent infections needs further investigation. An important gap of knowledge detected in this work is the lack of trials conducted on the effects of TRP on the microbiology of the digestive tract of poultry. Nevertheless, the little research performed in this area is promising, and thus new studies on this will be well welcomed. Feeding trials exploring the effects of TRP in conjunction with other healthy agents on gut microbiota and humoral immunity of poultry constitute the priority line of research on this subject to be developed in the future.

\section{Acknowledgements}

This work has been sponsored by the Prometeo Project, the Ministry of Higher Education, Science, Technology and Innovation of the Republic of Ecuador (SENESCYT). 


\section{References}

Abou-Elkhair R., Ahmed H.A., Selim S., 2014. Effects of black pepper (Piper nigrum), turmeric powder (Curcuma longa) and coriander seeds (Coriandrum sativum) and their combinations as feed additives on growth performance, carcass traits, some blood parameters and humoral immune response of broiler chickens. Asian-Australas. J. Anim. Sci. 27, 847-854, https:// doi.org/10.5713/ajas.2013.13644

Ahmad N., Fazal H., Abbasi B.H., Farooq S., Ali M., Khan M.A., 2012. Biological role of Piper nigrum L. (black pepper): a review. Asian Pac. J. Trop. Biomed. 2, S1945-S1953, https://doi org/10.1016/S2221-1691(12)60524-3

Ahmadi F., 2010. Effect of turmeric (Curcumin longa) powder on performance, oxidative stress state and some of blood parameters in broiler fed on diets containing aflatoxin B1. Glob. Vet. 5, 312-317

Akbarian A., Golian A., Kermanshahi H., Gilani A., Moradi S., 2012. Influence of turmeric rhizome and black pepper on blood constituents and performance of broiler chickens. Afr. J. Biotechnol. 11, 8606-8611

Akhavan-Salamat H., Ghasemi H.A., 2016. Alleviation of chronic heat stress in broilers by dietary supplementation of betaine and turmeric rhizome powder: dynamics of performance, leukocyte profile, humoral immunity, and antioxidant status. Trop. Anim. Health Prod. 48, 181-188, https://doi.org/10.1007/ s11250-015-0941-1

AL-Sultan S.I., Gameel A.A., 2004. Histopathological changes in the livers of broiler chicken supplemented with turmeric (Curcuma longa). Int. J. Poult. Sci. 3, 333-336, https://doi.org/10.3923/ ijps.2004.333.336

Ali S., Mukhtar M., Manzoor S., Hssain Z., Ali A., Tabassum R., Imran M., Amer M.Y., Bhatti N., 2014. Effect of garlic, black seed and turmeric on the growth of broiler chicken. Pak. J. Nutr. 13, 204-210, https://doi.org/10.3923/pjn.2014.204.210

Amalraj A., Pius A., Gopi S., Gopi S., 2017. Biological activities of curcuminoids, other biomolecules from turmeric and their derivatives - a review. J. Tradit. Complement. Med. 7, 205-233, https://doi.org/10.1016/j.jtcme.2016.05.005

Arshami J., Pilevar M., Azghadi M.A., Raji A.R., 2013. Hypolipidemic and antioxidative effects of curcumin on blood parameters, humoral immunity, and jejunum histology in Hy-line hens. Avicenna J. Phytomed. 3, 178-185

Ashayerizadeh O., Dastar B., Shams Shargh M., Rahmatnejad E., Ashayerizadeh A., 2009. Influence of prebiotic and two herbal additives on interior organs and hematological indices of broilers. J. Anim. Vet. Adv. 8, 1851-1855

Ayoub M.M., El-Far A.H., Taha N.M., Korshom M.A., Mandour A.A. Abdel-Hamid H.S., El-Neweshy M.S., 2011. The biochemica protective role of some herbs against aflatoxicosis in ducklings: I. Turmeric. Lucrări Ştiinţifice Ser. Zooteh. 55, 150-159

Bonafos L., Simonin D., Gavinelli A., 2010. Animal welfare: European legislation and future perspectives. J. Vet. Med. Educ. 37 26-29, https://doi.org/10.3138/jvme.37.1.26

Braun E.J., Sweazea K.L., 2008. Glucose regulation in birds. Comp. Biochem. Physiol. B Biochem. Mol. Biol. 151, 1-9, https://doi. org/10.1016/j.cbpb.2008.05.007

Chassagnez-Méndez A.L., Machado N.T., Araujo M.E., Maia J.G., Meireles M.A.A., 2000. Supercritical $\mathrm{CO}_{2}$ extraction of curcumins and essential oil from the rhizomes of turmeric (Curcuma longa L.). Ind. Eng. Chem. Res. 39, 4729-4733, https:// doi.org/10.1021/ie000171c

Chattopadhyay I., Biswas K., Bandyopadhyay U., Banerjee R.K., 2004. Turmeric and curcumin: Biological actions and medicinal applications. Curr. Sci. 87, 44-53
Chen D.-Y., Shien J.-H., Tiley L., Chiou S.-S., Wang S.-Y., Chang T.-J., Lee Y.-J. Chan K.-W., Hsu W.-L., 2010. Curcumin inhibits influenza virus infection and haemagglutination activity. Food Chem. 119, 1346-1351, https://doi.org/10.1016/j.foodchem.2009.09.011

Corzo-Martínez M., Corzo N., Villamiel M., 2007. Biological properties of onions and garlic. Trends Food Sci. Technol. 18, 609-625, https://doi.org/10.1016/j.tifs.2007.07.011

da Rocha M.E.B., Freire F.D.C.O., Maia F.E.F., Guedes M.I.F., Rondina D., 2014. Mycotoxins and their effects on human and animal health. Food Control 36, 159-165, https://doi. org/10.1016/j.foodcont.2013.08.021

Daneshyar M., Ghandkanlo M.A., Bayeghra F.S., Farhangpajhoh F., Aghaei M., 2011. Effects of dietary turmeric supplementation on plasma lipoproteins, meat quality and fatty acid composition in broilers. S. Afr. J. Anim Sci. 41, 420-428, https://doi. org/10.4314/sajas.v41i4.13

Emadi M., Kermanshahi H., 2007. Effect of turmeric rhizome powder on activity of some blood enzymes in broiler chickens. Int. J. Poult. Sci. 6, 48-51, https://doi.org/10.3923/ijps.2007.48.51

Emadi M., Kermanshahi H., Maroufyan E., 2007. Effect of varying levels of turmeric rhizome powder on some blood parameters of broiler chickens fed corn-soybean meal based diets. Int. J. Poult. Sci. 6, 345-348, https://doi.org/10.3923/ijps.2007.345.348

Éclache D., Etienne P., Noirot V., 2011. Effect of dietary antioxidant with controlled release on the performances of cold stressed broiler. In: Proceedings of the $9^{\text {th }}$ Poultry Research Days. Tours (France). World's Poultry Science Association (WPSA). Beekbergen (the Netherlands), pp. 29-30

Faghani M., Rafiee A., Namjoo A.R., Rahimian Y., 2014. Performance, cholesterol profile and intestinal microbial population in broilers fed turmeric extract. Res. Opin. Anim. Vet. Sci. 4, 500-503

Hosseini-Vashan S. J., Golian A., Yaghobfar A., 2015. Effects of turmeric rhizome powder and source of oil in diet on blood metabolites, immune system and antioxidant status in heat stressed broiler chickens. J. Livest. Sci. Technol. 3, 13-20

Hosseini-Vashan S.J., Golian A., Yaghobfar A., Zarban A., Afzali N., Esmaeilinasab P., 2012. Antioxidant status, immune system, blood metabolites and carcass characteristic of broiler chickens fed turmeric rhizome powder under heat stress. Afr. J. Biotechnol. 11, 16118-16125, https://doi.org/10.5897/AJB12.1986

Huang M.-T., Lysz T., Ferraro T., Abidi T.F., Laskin J.D., Conney A.H., 1991. Inhibitory effects of curcumin on in vitro lipoxygenase and cyclooxygenase activities in mouse epidermis. Cancer Res. 51, 813-819

Jobin C., Bradham C.A., Russo M.P., Juma B., Narula A.S., Brenner D.A., Sartor R.B., 1999. Curcumin blocks cytokine-mediated NF-kB activation and proinflammatory gene expression by inhibiting inhibitory factor I-kB kinase activity. J. Immunol. 163, 3474-3483

Jurenka J.S., 2009. Anti-inflammatory properties of curcumin, a major constituent of Curcuma longa: a review of preclinical and clinical research. Altern. Med. Rev.14, 141-153

Kermanshahi H., Riasi A., 2006. Effect of turmeric rhizome powder (Curcuma longa) and soluble NSP degrading enzyme on some blood parameters of laying hens. Int. J. Poult. Sci. 5, 494-498, https://doi.org/10.3923/ijps.2006.494.498

Khan R.U., Naz S., Javdani M., Nikousefat Z., Selvaggi M., Tufarelli V., Laudadio V., 2012. The use of turmeric (Curcuma longa) in poultry feed. Worlds Poult. Sci. J. 68, 97-103, https://doi. org/10.1017/S0043933912000104

Kilany O.E., Mahmoud M.M., 2014. Turmeric and exogenous enzyme supplementation improve growth performance and immune status of Japanese quail. Worlds Vet. J. 4, 20-29, https://doi. org/10.5455/wvj.20140841 
Kim D.K., Lillehoj H.S., Lee S.H., Jang S.I., Bravo D., 2010. Highthroughput gene expression analysis of intestinal intraepithelial lymphocytes after oral feeding of carvacrol, cinnamaldehyde, or Capsicum oleoresin. Poult. Sci. 89, 68-81, https://doi. org/10.3382/ps.2009-00275

Kumari P., Gupta M.K., Ranjan R., Singh K.K., Yadava R., 2007. Curcuma longa as feed additive in broiler bird and its patho-physiological effects. Indian J. Exp. Biol. 45, 272-277

Landers T.F., Cohen B., Wittum T.E., Larson E.L., 2012. A review of antibiotic use in food animals: perspective, policy, and potential. Public Health Rep. 127, 4-22, https://doi. org/10.1177/003335491212700103

Laurent S.M., Sanders R.N., 1988. U.S. Patent No. 4,759,932: Method of reducing heat stress in animals. United States Patent and Trademark Office. Alexandria, VA (USA)

Lee S.H., Lillehoj H.S., Jang S.I., Kim D.K., Ionescu C., Bravo D., 2010. Effect of dietary Curcuma, Capsicum, and Lentinus on enhancing local immunity against Eimeria acervulina infection. J. Poult. Sci. 47, 89-95, https://doi.org/10.2141/jpsa.009025

Lee S.H., Lillehoj H.S., Jang S.I., Lillehoj E.P., Min W., Bravo D.M., 2013. Dietary supplementation of young broiler chickens with Capsicum and turmeric oleoresins increases resistance to necrotic enteritis. Br. J. Nutr. 110, 840-847, https://doi.org/10.1017/ S0007114512006083

Lin H., Jiao H.C., Buyse J., Decuypere E., 2006. Strategies for preventing heat stress in poultry. Worlds Poult. Sci J. 62, 71-86, https:// doi.org/10.1079/WPS200585

Mahejabin N., Mostofa M., Akter F., Das S., Alam M., 2015. Effects of neem, turmeric and papaya leaf extract mixture on growth performance of broilers. Int. J. Nat. Soc. Sci. 2, 17-21

Main D.C.J., 2009. Application of welfare assessment to commercial livestock production. J. Appl. Anim. Welf. Sci. 12, 97-104, https://doi.org/10.1080/10888700902719658

Malekizadeh M., Moeini M.M., Ghazi S., 2012. The effects of different levels of ginger (Zingiber officinale Rosc) and turmeric (Curcuma longa Linn) rhizomes powder on some blood metabolites and production performance characteristics of laying hens. J. Agric. Sci. Technol. 14, 127-134

Mehala C., Moorthy M., 2008. Effect of Aloe vera and Curcuma longa (turmeric) on carcass characteristics and biochemical parameters of broilers. Int. J. Poult. Sci. 7, 857-861, https://doi. org/10.3923/ijps.2008.857.861

Mirbod M., Mahdavi A.H., Samie A.-H., Mehri M., 2017. Effects of Curcuma longa rhizome powder on egg quality, performance, and some physiological indices of laying hens fed different levels of metabolizable energy. J. Sci. Food Agric. 97, 1286-1294, https://doi.org/10.1002/jsfa.7862

Mirunalini S., Krishnaveni M., 2010. Therapeutic potential of Phyllanthus emblica (amla): the ayurvedic wonder. J. Basic Clin. Physiol. Pharmacol. 21, 93-105, https://doi.org/10.1515/JBCPP.2010.21.1.93

Moomivand H., Bassami M.R., Faramarzi S., Stabraghi E., Ghaedi A., Ghabel H., Zarghami A., Banaei M., 2013. Serological and clinical survey of Newcastle disease in broiler chickens of east Azarbayjan by $\mathrm{HI}$ tests. Eur. J. Exp. Biol. 3, 311-314

Musa H.H., Chen G.H., Cheng J.H., Yousif G.M., 2007. Relation between abdominal fat and serum cholesterol, triglycerides, and lipoprotein concentrations in chicken breeds. Turk. J. Vet. Anim. Sci. 31, 375-379

Nayaka H.B.S., Umakantha B., Ruban S.W., Murthy H.N.N., Narayanaswamy H.D., 2013. Performance and hematological parameters of broilers fed neem, turmeric, vitamin e and their combinations. Emir. J. Food Agric. 25, 483-488, https://doi.org/10.9755/ejfa. v25i6.15514
Nouzarian R., Tabeidian S.A., Toghyani M., Ghalamkari G., Toghyani M., 2011. Effect of turmeric powder on performance, carcass traits, humoral immune responses, and serum metabolites in broiler chickens. J. Anim. Feed Sci. 20, 389-400, https://doi. org/10.22358/jafs/66194/2011

Ognik K., Krauze M., 2016. The potential for using enzymatic assays to assess the health of turkeys. Worlds Poult. Sci. J. 72, 535-550, https://doi.org/10.1017/S0043933916000246

Ohtsu H., Yamazaki M., Abe H., Murakami H., Toyomizu M., 2015. Heat stress modulates cytokine gene expression in the spleen of broiler chickens. J. Poultry Sci. 52, 282-287, https://doi. org/10.2141/jpsa.0150062

Palaniappan K., Holley R.A., 2010. Use of natural antimicrobials to increase antibiotic susceptibility of drug resistant bacteria. Int. J. Food Microbiol. 140, 164-168, https://doi.org/10.1016/j.ijfoodmicro.2010.04.001

Patel S., Goyal A., 2011. Functional oligosaccharides: production, properties and applications. World J. Microbiol. Biotechnol. 27, 1119-1128, https://doi.org/10.1007/s11274-010-0558-5

Prakash P., Gupta N., 2005. Therapeutic uses of Ocimum sanctum Linn (tulsi) with a note on eugenol and its pharmacological actions: a short review. Indian J. Physiol. Pharmacol. 49, 125-131

Price K.R., Guerin M.T., Newman L., Hargis B.M., Barta J.R., 2013. Examination of a novel practical poultry management method to enhance the effect of live Eimeria vaccination for conventionally housed replacement layer pullets. Int. J. Poult. Sci. 12, 175-184, https://doi.org/10.3923/ijps.2013.175.184

Qasem M.A.A., Alhajj M.S., Ger El Nabi A.R., Al-Mufarrej S.I., 2015. Effect of turmeric powder as a dietary supplement on performance indicators and immune responses in broiler chickens. J. Anim. Vet. Adv. 14, 30-35

Rajput N., Muhammad N., Yan R., Zhong X., Wang T., 2013. Effect of dietary supplementation of curcumin on growth performance, intestinal morphology and nutrients utilization of broiler chicks. J. Poult. Sci. 50, 44-52, https://doi.org/10.2141/jpsa.0120065

Ravindran P.N., Nirmal Babu K., Sivaraman K., 2007. Turmeric, the Genus Curcuma. CRC Press. Boca Raton, FL (USA)

Rawal S., Kim J.E., Coulombe R. Jr., 2010. Aflatoxin $B_{1}$ in poultry: toxicology, metabolism and prevention. Res. Vet. Sci. 89, 325-331, https://doi.org/10.1016/j.rvsc.2010.04.011

Riasi A., Kermanshahi H., Mahdavi A.H., 2012. Production performance, egg quality and some serum metabolites of older commercial laying hens fed different levels of turmeric rhizome (Curcuma longa) powder. J. Med. Plants Res. 6, 2141-2145, https://doi.org/10.5897/JMPR11.1316

Sahin K., Orhan C., Tuzcu Z., Tuzcu M., Sahin N., 2012. Curcumin ameliorates heat stress via inhibition of oxidative stress and modulation of Nrf2/HO-1 pathway in quail. Food Chem. Toxicol. 50, 4035-4041, https://doi.org/10.1016/j.fct.2012.08.029

Salem M.L., 2005. Immunomodulatory and therapeutic properties of the Nigella sativa L. seed. Int. Immunopharmacol. 5, 1749-1770, https://doi.org/10.1016/j.intimp.2005.06.008

Samarasinghe K., Wenk C., Silva K.F.S.T., Gunasekera J.M.D.M., 2003. Turmeric (Curcuma longa) root powder and mannanoligosaccharides as alternatives to antibiotics in broiler chicken diets. Asian-Australas. J. Anim. Sci. 16, 1495-1500, https:// doi.org/10.5713/ajas.2003.1495

Santoso U., Kususiyah K., Suharyanto S., 2015. The effect of Sauropus androgynus leaves extract plus turmeric powder on fat deposition, carcass quality and blood profile in broilers fed low protein diets. J. Indones. Trop. Anim. Agric. 40, 121-130, https:// doi.org/10.14710/jitaa.40.2.121-130 
Saraswati T.R., Manalu W., Ekastuti D.R., Kusumorini N., 2013. Increased egg production of Japanese quail (Cortunix japonica) by improving liver function through turmeric powder supplementation. Int. J. Poult. Sci. 12, 601-614, https://doi. org/10.3923/ijps.2013.601.614

Sharma J.M., 1991. Overview of the avian immune system. Vet. Immunol. Immunopathol. 30, 13-17, https://doi.org/10.1016/01652427(91)90004-V

Simaraks S., Chinrasri O., Aengwanich W., 2004. Hematological, electrolyte and serum biochemical values of the Thai indigenous chickens (Gallus domesticus) in northeastern, Thailand. Songklanakarin J. Sci. Technol, 26, 425-430

Singh V.S., Palod J., Shukla P K., Kumar R.R., 2009. Influence of turmeric with alum on growth performance, haematological and parasitological parameters of broilers experimentally infected with mixed Eimeria species. Indian J. Anim. Prod. Manag. 25, 66-69

Sogi D.S., Sharma S., Oberoi D.P.S., Wani I.A., 2010. Effect of extraction parameters on curcumin yield from turmeric. J. Food Sci. Technol. 47, 300-304, https://doi.org/10.1007/s13197-0100047-8

Sugiharto S., Isroli I., Widiastuti E., Prabowo N.S., 2011. Effect of turmeric extract on blood parameters, feed efficiency and abdominal fat content in broilers. J. Indones. Trop. Anim. Agric. 36, 21-26, https://doi.org/10.14710/jitaa.36.1.21-26

Swathi B., Gupta P.S.P., Nagalakshmi D., 2012b. Effect of tulsi (Ocimum sanctum) and turmeric (Curcuma longa) on broiler performance and blood constituents during heat stress in broilers. Int. J. Pharm. Bio Sci. 3, 446-453

Swathi B., Gupta P.S.P., Nagalakshmi D., Reddy A.R., 2012a. Effect of herbals tulsi and turmeric on cortisol, enzymatic and biochemical constituents in serum of heat stressed broilers. Indian J. Anim. Nutr. 29, 284-286

Tirupathi Reddy E., Sudhakar Reddy P., Ramya P., Nagaraja Kumari K., 2012. Effect of supplementation of amla, tulsi and turmeric on bio-chemical parameters and immune responses in broilers. Indian J. Poult. Sci. 47, 114-117

Tsahar E., Arad Z., Izhaki I., Guglielmo C.G., 2006. The relationship between uric acid and its oxidative product allantoin: a potential indicator for the evaluation of oxidative stress in birds. J. Comp. Physiol. B 176, 653-661, https://doi.org/10.1007/ s00360-006-0088-5
Van Boeckel T.P., Brower C., Gilbert M., Grenfell B.T., Levin S.A., Robinson T.P., Laxminarayan R., 2015. Global trends in antimicrobialuseinfoodanimals.Proc.Nat.Acad.Sci.U.S.A.112, 5649-5654, https://doi.org/10.1073/pnas.1503141112

Wang D., Huang H., Zhou L., Li W., Zhou H., Hou G., Liu J., Hu L., 2015. Effects of dietary supplementation with turmeric rhizome extract on growth performance, carcass characteristics, antioxidant capability, and meat quality of Wenchang broiler chickens. Ital. J. Anim. Sci. 14, 344-349, https://doi. org/10.4081/ijas.2015.3870

Wangensteen H., Samuelsen A.B., Malterud K.E., 2004. Antioxidant activity in extracts from coriander. Food Chem. 88, 293-297, https://doi.org/10.1016/j.foodchem.2004.01.047

WHO (World Health Organization), 2012. The Evolving Threat of Antimicrobial Resistance. Options for Action. WHO. Geneva (Switzerland)

Yarru L.P., Settivari R.S., Gowda N.K.S., Antoniou E., Ledoux D.R., Rottinghaus G.E., 2009. Effects of turmeric (Curcuma longa) on the expression of hepatic genes associated with biotransformation, antioxidant, and immune systems in broiler chicks fed aflatoxin. Poult. Sci. 88, 2620-2627, https://doi. org/10.3382/ps.2009-00204

Yue G.G.L., Chan B.C.L., Hon P.-M., Kennelly E.J., Yeung S.K., Cassileth B.R., Fung K.-P., Leung P.-C., Lau C.B.S., 2010a. Immunostimulatory activities of polysaccharide extract isolated from Curcuma longa. Int. J. Biol. Macromol. 47, 342-347, https://doi.org/10.1016/j.ijbiomac.2010.05.019

Yue G.G.L., Chan B.C.L., Hon P.-M., Lee M.Y.H., Fung K.-P., Leung P.-C., Lau C.B.S., 2010b. Evaluation of in vitro antiproliferative and immunomodulatory activities of compounds isolated from Curcuma longa. Food Chem. Toxicol. 48, 2011-2020, https://doi.org/10.1016/j.fct.2010.04.039

Zeinali A., Kermanshahi H., Riasi A., Farhangfar H., Sarir H., Ziaie H., 2011. Effects of sodium selenite and turmeric powder on thyroid hormones and plasma lipids of broiler chickens reared under heat stress condition. Glob. Vet. 6, 237-240

Zhang D., Luo J.-y., Dan Y.A.N., Cheng J.I.N., Dong X.-p., Xiao X.-h., 2012. Effects of two curcuminoids on Candida albicans. Chin. Herb. Med. 4, 205-212, https://doi.org/10.3969/j.issn.16746384.2012 .03 .006 